\title{
First record of cysts in the tidal tardigrade Echiniscoides sigismundi
}

\author{
Lykke K. B. Clausen - Kasper N. Andersen • \\ Thomas L. Hygum • Aslak Jørgensen • \\ Nadja Møbjerg
}

Received: 14 February 2014/Revised: 14 July 2014/Accepted: 15 July 2014/Published online: 14 August 2014

(C) The Author(s) 2014. This article is published with open access at Springerlink.com

\begin{abstract}
Tardigrades are microscopic metazoans that withstand environmental extremes by entering dormant states, such as cryptobiosis (latent life). In addition, they may also form cysts. Here, we present the first report of cyst formation in a marine heterotardigrade, i.e., Echiniscoides sigismundi, which constitutes a cryptic species complex present worldwide in tidal zones. The cysts were initially discovered during experimental series constructed to investigate osmotic stress tolerance. The animals, which eventually formed cysts, showed signs of an imminent molt at the beginning of experimentation. We use the term "cyst" for stages, where a total of three or more cuticles have been synthesized. Our observations show that encystment in E. sigismundi involves synthesizing of at least two new cuticle layers. Legs with discharged claws are present in connection with the first outer cuticle, as well as the second cuticular layer. In the most developed cyst, a third cuticle lacking claws seems to surround the animal, which is delineated by a fourth cuticle. Many features are shared with the well-studied cysts of eutardigrades. The cysts of E. sigismundi, however, lack pigmentation and have an extra set of claws, and the animal inside retains buccopharyngeal sclerified parts, until discharging the third cuticle. The finding of cysts in a marine heterotardigrade is novel and confirms that encystment also occurs within this major evolutionary lineage.
\end{abstract}

Communicated by H.-D. Franke.

L. K. B. Clausen · K. N. Andersen - T. L. Hygum ·

A. Jørgensen · N. Møbjerg ( $\square)$

Department of Biology, August Krogh Centre, University of

Copenhagen, August Krogh Building, Universitetsparken 13,

2100 Copenhagen $\varnothing$, Denmark

e-mail: nmobjerg@bio.ku.dk
Keywords Diapause $\cdot$ Ecdysozoa $\cdot$ Extreme environments · Intertidal · Marine · Osmotic stress

\section{Introduction}

Tardigrades are microscopic metazoans that colonize ecosystems worldwide and show great tolerance of environmental stress (e.g., Goldstein and Blaxter 2002; Nelson 2002; Møbjerg et al. 2011). Three major evolutionary lineages are currently recognized: (1) eutardigrades and (2) mesotardigrades, which are predominantly semiterrestrial/ limnic, and (3) heterotardigrades that split into the semiterrestrial/tidal echiniscoideans and the marine arthrotardigrades. Tardigrades endure extremes, such as desiccation and freezing by entering dormant states, which include quiescence (cryptobiosis) and diapause (e.g., encystment). Noticeably, tardigrades comprise one of few phyla that exhibit both types of dormancy (Guidetti et al. 2008). Little attention has been dedicated to encystment, and the phenomenon has mainly been described from a few limnic and semiterrestrial species belonging to Eutardigrada (see, e.g., Weglarska 1957; Ramazzotti and Maucci 1983; Westh and Kristensen 1992; Guidetti et al. 2006). An aberrant cyst is found in the marine eutardigrade Halobiotus crispae Kristensen, 1982 as part of a seasonal change in morphology and physiology-i.e., cyclomorphosis (Kristensen 1982; Møbjerg et al. 2007; Halberg et al. 2009; Guidetti et al. 2011; Halberg et al. 2013a). In addition, within the heterotardigrades, cyst formation has been reported from moss-dwelling species of the genus Echiniscus C.A.S. Schultze, 1840 (Murray 1907; Ramazzotti and Maucci 1983). Importantly, cyst formation in tardigrades is mostly an optional response to environmental changes; however, when occurring during cyclomorphosis, it seems to be an 
obligate and integrated part of the seasonal change (Kristensen 1982; Møbjerg et al. 2007). In H. crispae, cyclomorphosis is apparently directed by changes in temperature (Halberg et al. 2013a).

Tardigrades belong to Ecdysozoa-a large clade of protostomes that shed their exoskeleton during growth (Aguinaldo et al. 1997). Based on investigations in eutardigrades, cyst formation shares many characteristics with the normal molting process, beginning with the discharge of buccopharyngeal sclerified parts and closing of the mouth (simplex stage), followed by synthesis of a new cuticle (Kristensen 1982; Walz 1982; Guidetti et al. 2008). However, instead of discharging the old cuticle (exuvium), as in a molt, a tardigrade in the process of encystment may secrete up to three new cuticles and keep the old ones as protective coats. The final cyst is generally oval shaped, with mouth and cloaca closed by cuticular invaginations and/or thickenings (Bertolani et al. 2004; Guidetti et al. 2006). From outside to inside, the cuticle layers forming eutardigrade cysts have been referred to as (1) old cuticle (exuvium), (2) sarcophagus cuticle and (3) mummy cuticle (Hansen and Katholm 2002; Guidetti et al. 2006). Interestingly, eutardigrades, e.g., species within the genus Bertolanius Özdikmen, 2008, may produce more than one type of cyst according to season (Westh and Kristensen 1992; Guidetti et al. 2006). The outermost cuticle of eutardigrade cysts becomes sclerotized and opaque during the encystment process (Guidetti et al. 2011), with pigmentation varying both among and within species. Cysts of Bertolanius volubilis (Durante Pasa and Maucci, 1975) are generally white-opaque, orange-yellow, red-purple or brown, while Dactylobiotus parthenogeneticus Bertolani, 1982 cysts typically display a brown-black coloration (Weglarska 1957; Guidetti et al. 2006).

Here, we present evidence of cyst formation in Echiniscoides sigismundi (M. Schultze, 1865), thereby consolidating that encystment also occurs within the major evolutionary lineage comprising the heterotardigrades.

\section{Methods and materials}

The genus Echiniscoides Plate, 1888 comprises cryptic species complexes with huge genetic variation (Faurby et al. 2011, 2012). In the present study, we describe cyst formation in Echiniscoides sigismundi sampled at two localities: Roscoff, France in July $2012\left(48^{\circ} 43^{\prime} 30^{\prime \prime} \mathrm{N}\right.$, $\left.03^{\circ} 59^{\prime} 35^{\prime \prime} \mathrm{W}\right)$ and Lynæs, Denmark in 2012 and 2013 $\left(55^{\circ} 56^{\prime} 42^{\prime \prime} \mathrm{N}, 11^{\circ} 51^{\prime} 15^{\prime \prime} \mathrm{E}\right)$. We use the term "cyst" for stages of the encystment process where three or more cuticles have been synthesized. Echiniscoides sigismundi from the two localities seems to undergo similar cyst formation.

Echiniscoides sigismundi on barnacles was collected from rocks in the tidal zone. Soft tissue was removed from barnacle shells in the laboratory, and the shells were subsequently washed and sieved through a $62-\mu \mathrm{m}$ mesh, thereby filtering bacteria, microalgae, ciliates and fine detritus from the material. The shells containing numerous tardigrades were transferred to seawater from the locality and kept at approximately $4{ }^{\circ} \mathrm{C}$ (Lynæs) and $17{ }^{\circ} \mathrm{C}$ (Roscoff). Temperature and salinity was $17^{\circ} \mathrm{C}$ and $35 \%$ at the time of sampling at Roscoff, and in the range $0.5-15^{\circ} \mathrm{C}$ and 16-20\%o at the time of sampling at Lynæs.

The cysts were initially discovered following exposures to various salinities during experiments constructed to investigate osmotic stress tolerance (Table 1). During these experiments, single specimens were transferred to glass slides at given time points and thus followed over time at high magnification. A Leica DM1000 microscope equipped with a digital camera (InfinityX, Deltapix, Denmark) was used for the investigation. Specifically, single tardigrades were monitored and photographed in seawater from their locality ( $t=0 \mathrm{~h} ; 35 \%$ Roscoff, $16 \%$ Lynæs), three times during a subsequent 48 -h exposure to a given test salinity ( $t=2 \mathrm{~h}, t=24 \mathrm{~h}$ and $t=48 \mathrm{~h}$ ), and up to three times following retransfer to normal seawater $(t=50 \mathrm{~h}$, $t=72 \mathrm{~h}$ and $t=96 \mathrm{~h}$ ). A total of four cysts, two from

Table 1 Specific information on the specimens reported in the current study

\begin{tabular}{|c|c|c|c|c|c|}
\hline Specimen & Sampling (month and year) & Experimental treatment & Cuticle layers & Buccopharyngeal apparatus & Remarks \\
\hline L1 & March 2013 & Hypotonic & 3 & Aberrant & Least developed \\
\hline L2 & September 2012 & Hypertonic & 3 & Normal & \\
\hline L3 & September 2013 & No treatment & 3 & Normal & \\
\hline L4 & November 2013 & Hypotonic/desiccation & 3 & Normal & \\
\hline $\mathrm{R} 2$ & July 2012 & Hypertonic & 3 & Normal & \\
\hline R1 & July 2012 & Hypotonic & 4 & Aberrant $^{\mathrm{a}}$ & Most developed \\
\hline
\end{tabular}

Tardigrades were sampled at Lynæs (Denmark) and Roscoff (France) and are accordingly designated with an "L" or "R". The status of the buccopharyngeal apparatus and cuticle layers refer to the latest stage of encystment observed for the given specimen. The number of cuticle layers includes the animal cuticle

${ }^{\text {a }}$ Sclerified parts discharged into second cuticle 
Roscoff (specimens R1 and R2) and two from Lynæs (specimens L1 and L2) were found during these experiments (Fig. 1). Specimens R1 and L1 were exposed to hypotonic solutions (3.5 and $1.6 \%$ ) during the 48 -h period in test salinities, while R2 and L2 were exposed to a hypertonic solution (70 \%o) during this time interval. The cysts of R1 and R2 are preserved as permanent mounts in glycerol on glass slides.

Several additional cysts were subsequently discovered in the Lynæs material kept at $4{ }^{\circ} \mathrm{C}$, two of which are documented here (L3 and L4). L3 had been kept for approximately 1 week in a watch glass together with numerous other specimens, organic material from barnacles and small algae. A considerable amount of microbial growth as well as free-moving ciliates were present at the time of discovery (Fig. 2a-c). The other specimen (L4) had been kept for approximately 1 day in a watch glass, then exposed to distilled water for an hour, dehydrated on a filter for $48 \mathrm{~h}$ and subsequently rehydrated with $18 \%$ seawater. The cyst was discovered $48 \mathrm{~h}$ after rehydration (Fig. 2d, e).

\section{Results}

In the following, we describe in detail the four specimens, which formed cysts in connection with osmotic stress experiments. Figure 3 illustrates cyst formation in Echiniscoides sigismundi based on the observation of these specimens.

At the onset of the experiments, $(t=0 \mathrm{~h})$ newly synthesized claws, and a clear double cuticle, could be seen in $\mathrm{R} 1$ and R2. In L2, an extra cuticle was visible at the onset of experimentation $(t=0 \mathrm{~h})$, while new claws were visible in L1 two hours after exposure to the hypotonic solution $(t=2 \mathrm{~h})$. Clear cyst formation, in which at least two cuticle coats surrounded the animal, was visible in $\mathrm{R} 1$ and R2, $72 \mathrm{~h}$ after experimental start (Fig. 1c, d), while cyst formation in L1 and L2 appeared at $t=96 \mathrm{~h}$ and $t=50 \mathrm{~h}$, respectively (Fig. 1a, b). At these time points, the animals had contracted into a "tun"-like state, positioned in the posterior/central (R2 and R1) to central (L2) part of the cyst (Fig. 1b-d). The tardigrade in L1 was, however, not fully contracted (Fig. 1a, $t=96 \mathrm{~h}$ ), and we interpreted the cyst of L1 as being the least developed of the observed cysts.

At $t=96 \mathrm{~h}$, the tardigrade in L1 had an abnormally formed pharyngeal bulb, indicating a recent discharge of sclerified parts, with new cuticular parts of the bulb not yet fully reconstructed (Fig. 1a). At this time point, L1 had an outer cuticular coat with a newly synthesized cuticle beneath it. This second cuticle was in the process of being discharged, and a third cuticle lined the animal. Cysts L2
(Fig. 1b) and R2 (Fig. 1c) had three cuticle layers at $t=72 \mathrm{~h}$. If the terminology used for eutardigrades (Guidetti et al. 2006) is applied, the two newly synthesized layers would correspond to, respectively, the sarcophagus and the animal body cuticle, which are both surrounded by the old outer cuticle. R1 seemed to have four cuticle layers at $t=72 \mathrm{~h}$; three layers of protective coats and a fourth cuticle lining the animal (Fig. 1d). Old claws were found discharged with the exuvium in all cysts. Legs formed by the second cuticle were clearly visible in L2, R2 and R1 and, noticeably, contained an additional set of claws. These claws had been discharged from the animals together with the second cuticle layer. Thickenings on the discharged cuticles clearly marked the region of the anus in L2 (Fig. 1b, $t=72$ ). The animals inside L2 and R2 had a cuticle-lined pharyngeal bulb with readily visible placoids and stylets. In R1, a structure recognized as the cuticular lining of the pharyngeal bulb with placoids was visible in the anterior region of the cyst within the second cuticle (Fig. 1d, $t=72$ ). We did not find evidence of discharged sclerified elements within the other $E$. sigismundi cysts.

During our observations, the animals within the cysts were moving, however, with reduced activity compared with experimental onset. Reduced activity was a general feature of the tardigrades following experimentation with osmotic stress and no food access. No color changes were observed, apart from the emptying of some gut content (bright yellow) into the discharged second cuticle in L2 (Fig. $1 \mathrm{~b}, t=50 \mathrm{~h}$ ).

The two additional cysts, L3 and L4, had two outer cuticle layers (both with claws), in addition to the animal cuticle (Fig. 2). Moreover, both cysts had a well-developed buccopharyngeal apparatus with clearly visible stylets, buccal tube and placoids. None of the animals left their cysts while being observed.

\section{Discussion}

Echiniscoides sigismundi is a common marine heterotardigrade, which inhabits barnacles, algae and lichens in tidal zones worldwide. Consequently, this species may experience large fluctuations in temperature and osmotic pressure, especially during low tides. The marine family Echiniscoididae, comprising Echiniscoides and another genus (Anisonyches Pollock, 1975), is phylogenetically basal in the clade Echiniscoidea, which also includes a large and diverse group of terrestrial tardigrades (Jørgensen et al. 2010, 2011). Echiniscoides sigismundi may thus provide an evolutionary link between sea and land. Terrestrial Echiniscus cysts have previously been observed (Murray 1907; Ramazzotti and Maucci 1983), and our 
observations on Echiniscoides sigismundi thus confirm that cyst formation occurs in echiniscoidean heterotardigrades. A similar pattern of encystment suggests that the differences observed among E. sigismundi cysts represent successive stages of encystment, rather than different cyst types, as known from, e.g., Bertolanius (see Westh and Kristensen 1992; Guidetti et al. 2006).

We show that Echiniscoides sigismundi is capable of producing cysts that in some aspects resemble cysts of limno-terrestrial eutardigrades. In the latter, the progression of encystment is generally associated with less activity and ultimately immobility of the tardigrade (Guidetti et al. 2006). Interestingly, however, cysts of the marine Halobiotus crispae (pseudosimplex 1 stage) remain mobile (Kristensen 1982). During our observations of encystment in E. sigismundi, the cysts were clearly immobile; however, the animals inside the cysts were moving. Markedly, the animal inside the most developed cyst, R1, was also moving. Despite this activity, it is likely that metabolism takes place at a slower rate than in active animals, as generally holds for diapausing animals (Guidetti et al. 2006).

Noticeably, Echiniscoides sigismundi cysts have a set of discharged claws in connection with both the first (outer) and the second cuticles (Fig. 2c). This has not been described for any eutardigrade species. In limnic eutardigrades, e.g., Dactylobiotus parthenogeneticus, the outermost cuticle has legs with distal positioned claws, the second (sarcophagus) cuticle has legs but no claws, while the third (mummy) cuticle lacks both legs and claws (Guidetti et al. 2006). "Type 2" cysts of the moss-dwelling Bertolanius volubilis have legs in the mummy cuticle, and both cysts ("type 1" and "type 2") in Bertolanius nebulosus (Dastych, 1983) lack the sarcophagus cuticle. Cyst morphology thus differs greatly among eutardigrades and a consensus eutardigrade cyst cannot be ascribed. Another example of cyst variation, observed among eutardigrades, is seen in D. parthenogeneticus, as this species often slugs off its old outer cuticle, leaving the hardened and pigmented sarcophagus cuticle as a protective barrier to the external environment (Guidetti et al. 2006).

Encysted Echiniscoides sigismundi seem to retain buccopharyngeal sclerified parts until shedding the third cuticle. In cysts of Dactylobiotus parthenogeneticus, stylets and structures associated with them (sheath and supports) are absent, while they are present, but greatly modified, in the cyst of B. volubilis (Guidetti et al. 2006). Eutardigrade cysts are generally characterized by opaque pigmentation (Guidetti et al. 2008), whereas encystment in E. sigismundi
Fig. 1 Cyst formation in Echiniscoides sigismundi induced by osmotic stress. a Dorsal view of the $L 1$ cyst with two cuticular coats ( $c 1$ and $c 2$ ). The animal has an abnormally formed pharyngeal bulb $(p b)$. b The response of $L 2$ to the osmotic stress series. The animal seemed ready to molt at the beginning of the experiment $(t=0 \mathrm{~h})$. It entered a "tun" state in the hypersaline solution $(70 \%, t=48 \mathrm{~h})$; however, instead of molting upon return to normal salinity (16\%o, $t=50 \mathrm{~h}$ ), it synthesized an additional cuticle layer. The animal finally retracted into a tun-like state within the cyst $(t=72 \mathrm{~h})$. Sclerified parts of the buccopharyngeal apparatus, e.g., stylets $(s t)$, are retained within the encysted animal. Note the extra set of claws $(n c)$ in connection with the second cuticle ( $c 2)$. $\mathbf{c} R 2$ seemed ready to molt at the beginning of experimentation $(t=0 \mathrm{~h})$, but following exposure to a hyperosmotic solution $(70 \%)$ it synthesized yet an extra cuticle $(t=72 \mathrm{~h}) . \mathbf{d} R 1$ at $t=72 \mathrm{~h}$ represented the most advanced stage of encystment that was observed. The animal seemed ready to molt before $(t=0 \mathrm{~h})$ exposure to a hyposmotic solution $(3.5 \%$, $t=24 \mathrm{~h})$. When returned to normal salinity (35\%) it synthesized what seemed to be two additional cuticles, and the animal thus appeared to be surrounded by three cuticular coats $(c 1, c 2$ and $c 3)$. It ultimately discharged stylets, placoids and pharyngeal bulb cuticle into $c 2$, a feature not seen in the other cysts. $b c$ bulb cuticle, $c 1-4$ cuticles $1-4, c l$ claws, $g u$ gut, $n c$ new claws, $p b$ pharyngeal bulb, $s t$ stylets

apparently does not involve color change. This difference in pigmentation could correlate with habitat, as limno-terrestrial tardigrades are likely exposed to higher levels of UV radiation.

True limnic eutardigrades, e.g., Dactylobiotus parthenogeneticus, as well as the marine Halobiotus crispae, form cysts but do not enter cryptobiosis, while Echiniscoides sigismundi as well as the semiterrestrial species are cryptobionts (Bertolani et al. 2004; Guidetti et al. 2006; Møbjerg et al. 2011). Cryptobiosis provides the ultimate means of resistance to environmental extremes and generally involves anatomical changes (Halberg et al. 2013b). Encysted tardigrades undergo major structural changes, and with reduced metabolism, the encysted state can also withstand adverse factors including desiccation and freezing (Weglarska 1957; Guidetti et al. 2011; Møbjerg et al. 2011).

Encystment is thought to be under endogenous control and may be initiated by changes in environmental factors such as temperature, $\mathrm{pH}$, oxygen tension and food availability (Bertolani et al. 2004; Guidetti et al. 2008). In the present study, five of the Echiniscoides sigismundi cysts were formed following osmotic stress treatments, suggesting that both hypo- and hypertonic stress represents adverse conditions that ultimately may stimulate cyst formation. A continuous internal osmotic imbalance thus seems to be yet another significant diapause inducing stimulus. 

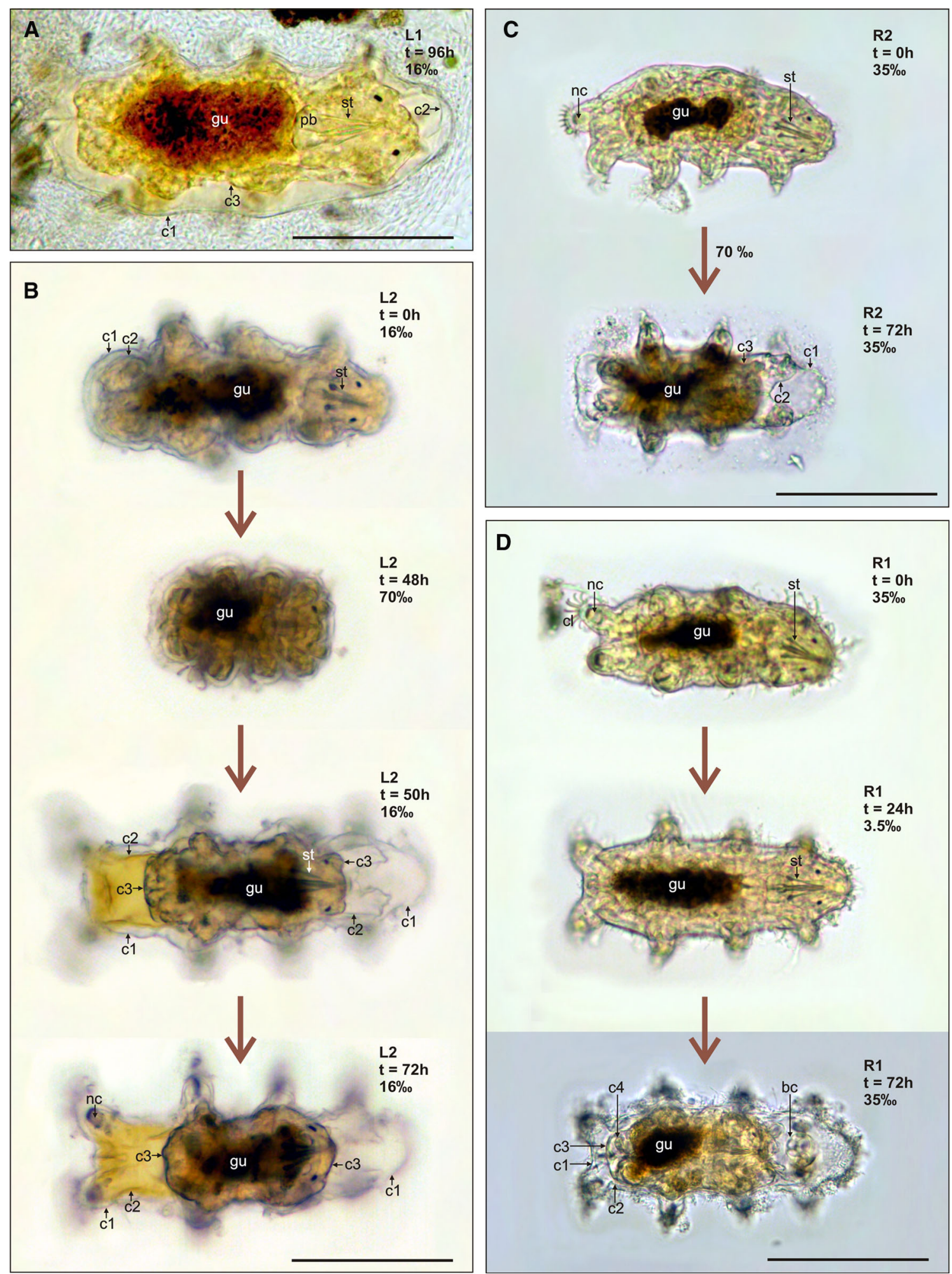

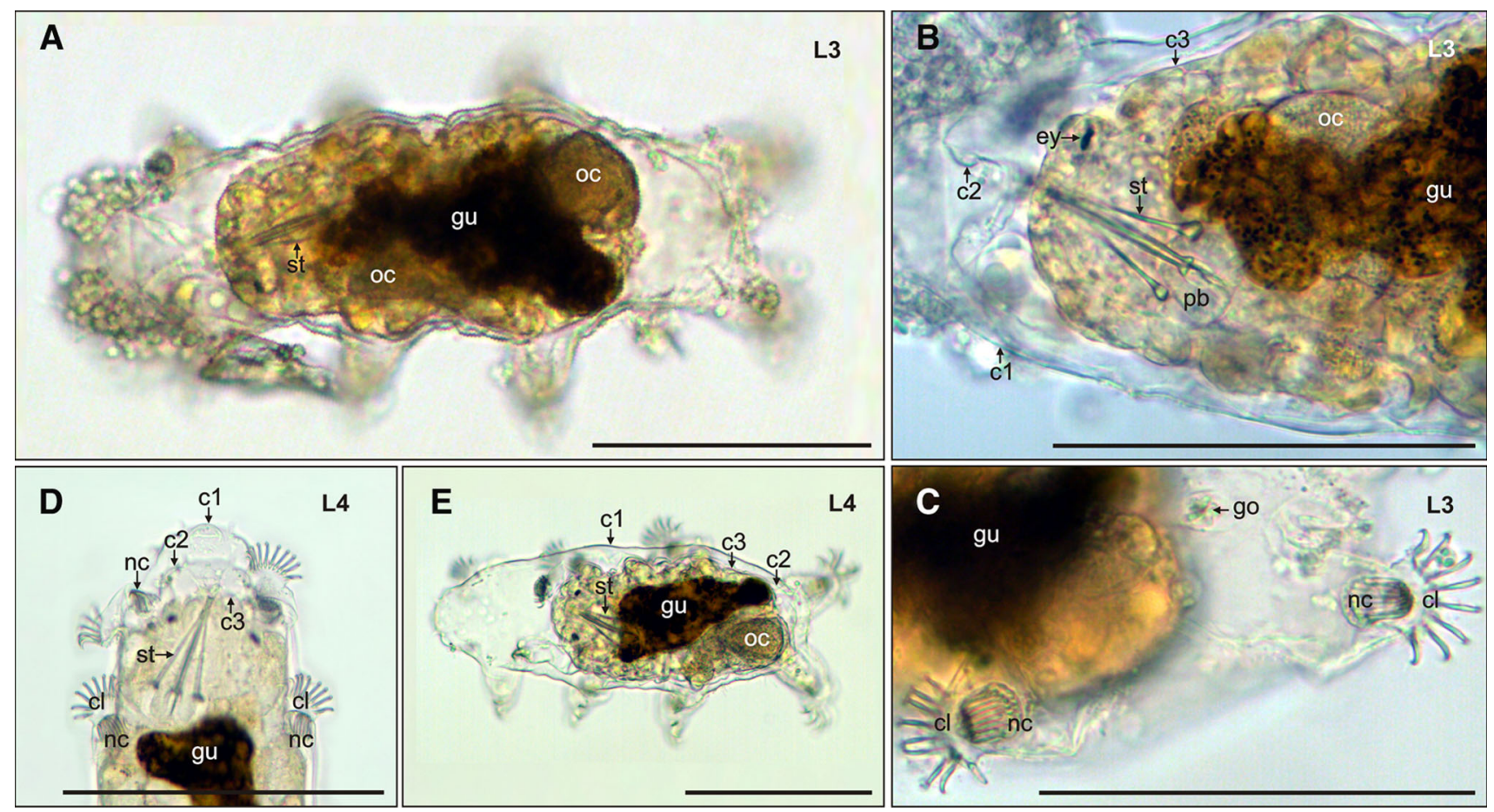

Fig. 2 Additional Echiniscoides sigismundi cysts. a Dorsal view of L3. The animal is surrounded by two cuticle coats and, although partly retracted, it was still moving within the cyst. Note microbial growth in the anterior part of the cyst. b Close up of the anterior region of $L 3$ revealing the buccopharyngeal apparatus. $\mathbf{c}$ Ventral view of posterior region of $L 3$ revealing the newly synthesized claws $(n c)$, which were discharged together with the second cyst cuticle. d Anterior end of $L 4$ showing the three cuticle layers, a functional buccopharyngeal apparatus and newly synthesized claws. Note the closed mouth of the outer cuticle $(c 1)$. e Dorsal view of $L 4$. The animal was moving within the outer cuticle $(c 1)$, while shedding the second cuticle ( $c 2)$. $c 1-3$ cuticles $1-3, c l$ claws, go gonopore, gu gut, $n c$ new claws, $p b$ pharyngeal bulb, $o c$ oocyte, st stylets

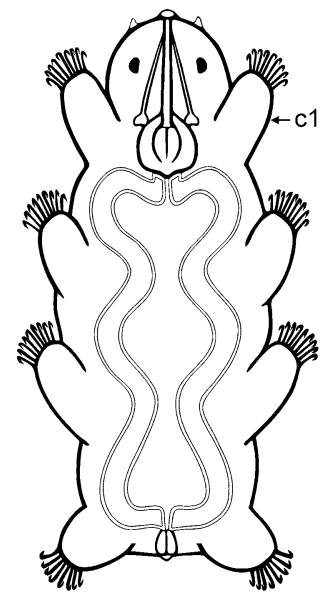

A

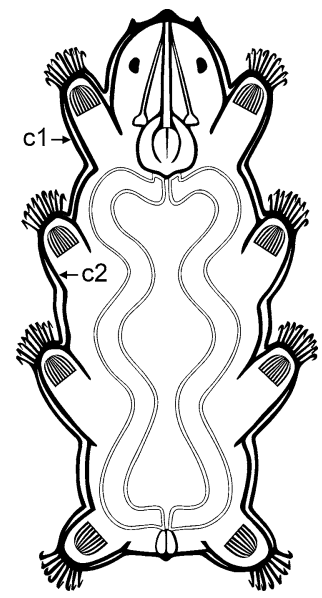

B

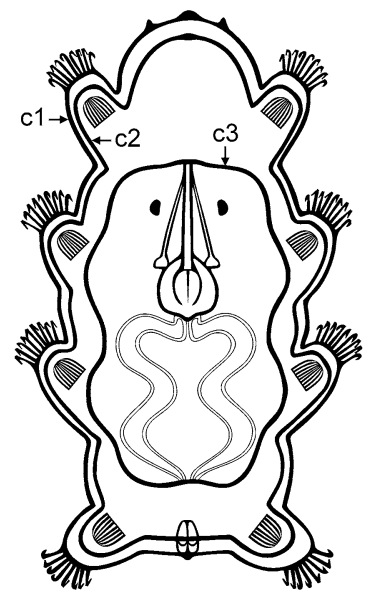

C

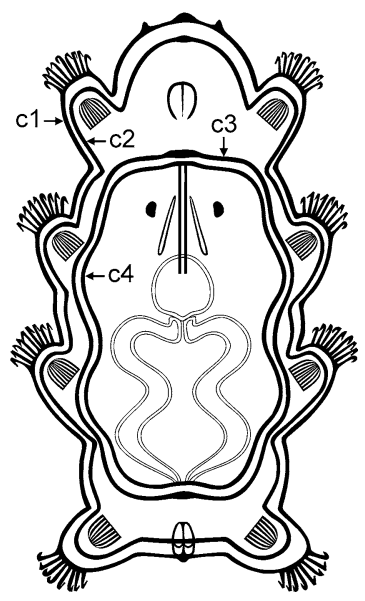

D

Fig. 3 Schematic representation of cyst formation in Echiniscoides sigismundi. The proposed encystment processes based on the six specimens observed in the present study (L1-4 and R1-2). a Active animal with a single cuticle $(c 1)$. b The first observed stage of encystment resembles a molting animal with newly synthesized claws and cuticle $(c 2)$ as well as a closed mouth and anus. It is reasonable to assume that a stage exists, between $\mathbf{a}$ and $\mathbf{b}$, in which buccopharyngeal sclerified parts have been discharged. Such a stage was, however,

not directly observed and thus it is not depicted in the current figure. c Cyst with two cuticular coats $(c 1-c 2)$ and an animal with fully developed buccopharyngeal apparatus retracted into a tun-like state. d Cyst, represented by $R 1$, with three cuticular coats $(c 1-c 3)$. The animal inside this cyst is lined with a fourth cuticle layer (c4) and sclerified parts of the buccopharyngeal apparatus have been discharged into $c 2$ 
Acknowledgments The current study was funded by the Carlsberg Foundation. Station Biologique de Roscoff (France) is warmly thanked for logistic support.

Open Access This article is distributed under the terms of the Creative Commons Attribution License which permits any use, distribution, and reproduction in any medium, provided the original author(s) and the source are credited.

\section{References}

Aguinaldo AMA, Turbeville JM, Linford LS, Rivera MC, Garey J, Raff RA, Lake JA (1997) Evidence for a clade of nematodes, arthropods and other moulting animals. Nature 387(6632):489-493

Bertolani R, Guidetti R, Jönsson IK, Altiero T, Boschini D, Rebecchi L (2004) Experiences with dormancy in tardigrades. J Limnol 63:16-25

Faurby S, Jørgensen A, Kristensen RM, Funch P (2011) Phylogeography of North Atlantic tidal tardigrades: refugia, cryptic speciation and the history of the Mid Atlantic islands. J Biogeogr 38:1613-1624

Faurby S, Jørgensen A, Kristensen RM, Funch P (2012) Distribution and speciation in marine intertidal tardigrades: testing the roles of climatic and geographical isolation. J Biogeogr 39:1596-1607

Goldstein B, Blaxter M (2002) Tardigrades. Curr Biol 12:R475

Guidetti R, Boschini D, Rebecchi L, Bertolani R (2006) Encystment processes and the "Matrioshka-like stage" in a moss-dwelling and in a limnic species of eutardigrades (Tardigrada). Hydrobiologia 558(1):9-21

Guidetti R, Boschini D, Altiero T, Bertolani R, Rebecchi L (2008) Diapause in tardigrades: a study of factors involved in encystment. J Exp Biol 211(14):2296-2302

Guidetti R, Altiero T, Rebecchi L (2011) On dormancy strategies in tardigrades. J Insect Physiol 57(5):567-576

Halberg KA, Persson D, Ramløv H, Westh P, Kristensen RM, Møbjerg N (2009) Cyclomorphosis in Tardigrada: adaptation to environmental constraints. J Exp Biol 212:2803-2811

Halberg KA, Persson DK, Jørgensen A, Kristensen RM, Møbjerg N (2013a) Ecology and thermal tolerance of the marine tardigrade Halobiotus crispae (Eutardigrada: Isohypsibiidae). Mar Biol Res 9(7):716-724

Halberg KA, Jørgensen A, Møbjerg N (2013b) Desiccation tolerance in the tardigrade Richtersius coronifer relies on muscle mediated structural reorganization. PLoS One 8(12):e85091
Hansen JG, Katholm AK (2002) A study of the genus Amphibolus from Disko Island with special attention on the life cycle of Amphibolus nebulosus (Eutardigrada: Eohypsibiidae). In: Hansen JG (ed) Arctic Biology Field Course Quqertarsuaq 2002. Zoological Museum University of Copenhagen H.C.Ø. TRYK, Copenhagen, pp 129-163

Jørgensen A, Faurby S, Hansen JG, Møbjerg N, Kristensen RM (2010) Molecular phylogeny of Arthrotardigrada (Tardigrada). Mol Phylogenet Evol 54:1006-1015

Jørgensen A, Møbjerg N, Kristensen RM (2011) Phylogeny and evolution of the Echiniscidae (Echiniscoidea, Tardigrada) - an investigation of the congruence between molecules and morphology. J Zool Syst Evol Res 49(Suppl 1):6-16

Kristensen RM (1982) The first record of cyclomorphosis in Tardigrada based on a new genus and species from Arctic meiobenthos. Z zool Syst Evolut-forsch 20:249-270

Møbjerg N, Jørgensen A, Eibye-Jacobsen J, Halberg KA, Persson D, Kristensen RM (2007) New records on cyclomorphosis in the marine eutardigrade Halobiotus crispae. J Limnol 66(Suppl 1): $132-140$

Møbjerg N, Halberg KA, Jørgensen A, Persson D, Bjørn M, Ramløv H, Kristensen RM (2011) Survival in extreme environments-on the current knowledge of adaptations in tardigrades. Acta Physiol 202(3):409-420

Murray J (1907) Encystment of Tardigrada. Trans R Soc Edinb 45:837-854

Nelson DR (2002) Current status of the Tardigrada: evolution and ecology. Integr Comp Biol 42:652-659

Ramazzotti G, Maucci W (1983) Il Phylum Tardigrada. Terza edizione riveduta e corretta. Memorie dell'Isituto Italiano di Idrobiologia Dott. Marco De Marchi 41:1-1012 (English translation by Clark W. Beasley)

Walz B (1982) Molting in tardigrada. A review including new results on cuticle formation in Macrobiotus hufelandi. In: Nelson DR (ed) Proceedings of the Third International Symposium on the Tardigrada. East Tennessee State University Press, Johnson City, Tennessee, pp 129-147

Weglarska B (1957) On the encystation in Tardigrada. Zool Pol $8: 315-325$

Westh P, Kristensen RM (1992) Ice formation in the freeze-tolerant eutardigrades Adorybiotus coronifer and Amphibolus nebulosus studied by differential scanning calorimetry. Polar Biol 12: 693-699 